\title{
Fermentation optimization and disease suppression ability of a Streptomyces ma. FS-4 from banana rhizosphere soil
}

\author{
Yajie Duan ${ }^{1}$, Jian Chen², Wei He${ }^{2}$, Jingjing Chen ${ }^{1}$, Zhencai Pang ${ }^{1}$, Huigang Hu${ }^{1 *}$ and Jianghui Xie ${ }^{1 *}$ (D)
}

\begin{abstract}
Background: Fusarium wilt of banana is one of the most destructive diseases in banana-growing regions worldwide. Soil-borne diseases and soil microbial communities are closely related. The screening of antagonistic bacteria from soil microorganisms in areas with Fusarium wilt of banana is of great practical significance for controlling this disease.

Results: A strain designated FS-4 was isolated from healthy banana rhizosphere soil in an area affected by Fusarium wilt. This strain exhibited a significant antagonistic effect on the pathogen. Pot experiments revealed that the fermentation broth of strain FS-4 not only decreased the incidence of banana Fusarium wilt, but also promoted the growth of banana seedlings. The strain was identified as Streptomyces ma. by its morphological, physiological, and biochemical characteristics and 165 rRNA gene sequence analysis. The culture and fermentation conditions for this strain were optimized by single-factor and response surface experiments. The optimum culture conditions for Streptomyces ma. FS-4 were as follows: peptone 0.5\%, saccharose 2.4, 0.05\% $\mathrm{K}_{2} \mathrm{HPO}_{4}, 0.05 \% \mathrm{MgCl}_{2}$, and $0.05 \% \mathrm{NaCl}$ at an initial $\mathrm{pH}$ of $7.0 ; 180 \mathrm{~g}$ at $28^{\circ} \mathrm{C}$; and inoculation size of $6 \%$ for $62 \mathrm{~h}$. The diameter of bacteriostasis circle for Bacillus subtilis reached $26.7 \mathrm{~mm}$.
\end{abstract}

Conclusion: Streptomyces ma. FS-4 is an important microbial resource as a biological agent for the control of plant pathogenic fungi and can be used to promote banana growth.

Keywords: Streptomyces manipurensis, Fusarium wilt of banana, FS-4, Antimicrobial activity, Culturing conditions

\section{Background}

Fusarium wilt of banana is a soil-borne disease caused by fungal infection (Fusarium oxysporum f. sp. cubense, $F o c$ ) of the banana root [1-3]. Since the 1990s, Fusarium wilt of banana has spread to the world's leading banana production areas and has become one of the most destructive banana diseases [4-6]. In recent years, Fusarium wilt of banana has spread in major areas of China, thereby seriously endangering the healthy and sustainable development of the banana industry [2, 5-7]. Fusarium wilt of banana is extremely infectious and difficult to cure. The pathogen has strong resistance to stress

\footnotetext{
* Correspondence: huhuigang@sina.com; 313972374@qq.com

'Key Laboratory of Tropical Fruit Biology, Ministry of Agriculture, Chinese Academy of Tropical Agricultural Science, South Subtropical Crop Research Institute, Zhanjiang 524091, China

Full list of author information is available at the end of the article
}

and can survive for 30 years in soil, thereby causing extensive destruction of orchards $[4,8,9]$.

Actinomycetes are widely distributed in natural ecosystems. They have various metabolic functions and are widely used as a biological resources [10-14]. Actinomycetes have long been an important source of bioactive metabolites. More than half of existing natural antibiotics are produced from actinomycetes (especially Streptomyces) [15-17]. However, among the antibiotics produced from actinomycetes, only extremely small doses will exert a significant effect and can effectively prevent and control a variety of infectious diseases in humans and livestock $[16,18,19]$. For agricultural disease control, researchers have screened different actinomycete strains from soils and plants. These strains can control turfgrass root rot [20], rice blast [21], rice leaf blight [18], and tomato gray mold [22] with good results. Moreover, the antimicrobial active substances in 
the metabolites of antagonistic actinomycetes are preliminarily isolated [17, 23, 24]. Roy et al. (2006) isolated dibutyl phthalate from Streptomyces fermentation liquid; this compound has a strong inhibitory effect on $\mathrm{G}^{+}$and $\mathrm{G}^{-}$bacteria and unicellular and filamentous fungi. Mingma et al. (2014) isolated actinomycetes from legumes fermentation liquid and identified phenylacetic acid as the active substance that inhibited the pathogen of soybean glycine Xanthomonas [14]. These results provided new ideas and approaches for the biological control of Fusarium wilt of banana.

The production level of microbial fermentation not only depends on the performance of the production strains, but also needs the best environmental conditions, i.e., the fermentation process, to fully display its production capacity [5]. Therefore, it is necessary to study the optimum fermentation process conditions for strain production, such as nutritional requirements, culture temperature, $\mathrm{pH}$ conditions, and time; accordingly, a reasonable fermentation process is designed for the production of strains under the best product synthesis conditions, thereby achieving high quality and yield [1].

In our study, an actinomycete strain with strong antagonistic effect on Fusarium wilt was identified from rhizosphere soil with severe banana disease, and its species relationship and fermentation conditions were studied. Our results provide an experimental basis for the separation and identification of antibiotics and the theoretical basis for their production and application.

\section{Methods}

\section{Sampling site and sample collection}

Twenty-five soil samples were collected from healthy banana rhizosphere soil in an area affected with Fusarium wilt of banana in Zhanjiang City, Guangdong Province in November of 2015. From a healthy plantain garden where bananas has been grown for more than 10 years, rhizosphere soil was collected at $10-30 \mathrm{~cm}$ of the root of healthy plants. Soil samples were collected and placed inside a sterile plastic bag, sealed, and preserved in an ice box. In the laboratory, the roots and stones were removed and stored at $4{ }^{\circ} \mathrm{C}$ before the actinomycetes were isolated.

Pathogenic fungi strains includes Fusarium oxysporum f. sp. cubense Race1 (FOC.1), F. oxysporum f. sp. cubense Race 4 (FOC.4), Curvulatia fallaxis (CFO), Colletotrichum gloeosporides (CG), and Alternaria tenuissima Maa (MAA), Escherichia coli (E. coli), Bacillus subtilis (B. subtilis), and Staphylococcus aureus (S. aureus)were provided by the Institute of Environment and Plant Protection. Taq PCR Master Mix and bacterial genomic DNA rapid extraction kit were purchased from Sigma-Aldrich Co. (USA).

"Gause's no. 1 culture": $20.0 \mathrm{~g}$ Soluble starch, $0.5 \mathrm{~g}$ $\mathrm{NaCl}, 1.0 \mathrm{~g} \mathrm{KNO}_{3}, 0.5 \mathrm{G} \mathrm{K}_{2} \mathrm{HPO}{ }_{4} \cdot 3 \mathrm{H}_{2} \mathrm{O}, 0.5 \mathrm{~g} \mathrm{MgSO}$ ${ }_{4} \cdot 7 \mathrm{H}_{2} \mathrm{O}, 0.01 \mathrm{~g} \mathrm{FeSO}_{4} \cdot 7 \mathrm{H}_{2} \mathrm{O}, 20 \mathrm{~g}$ agar, $1000 \mathrm{~mL} \mathrm{H}_{2} \mathrm{O}$

\section{Isolation and purification of actinomycetes}

Actinomycetes were isolated by serial dilution method on Gause's no. 1 culture [13, 19, 21, 24, 25], which was sterilized at $121^{\circ} \mathrm{C}$ for $20 \mathrm{~min}$, static, and cooled to room temperature. In total, $3 \mathrm{~mL}$ of $1 \%$ dichromate solution after filter sterilizer was added to the culture (per liter); $0.5 \mathrm{~mL}$ of $5 \%$ mycetin was set aside for reverse plate. Soil sample at $10 \mathrm{~g}$ was dissolved in $100 \mathrm{~mL}$ aseptic water. The suspension was mixed well and then diluted 10 times to prepare $10^{-4}, 10^{-5}$, and $10^{-6}$ suspension. Next, $0.1 \mathrm{~mL}$ of suspension was added to the Gause's no. 1 culture. The gradient was set to three iterations and incubated at $28^{\circ} \mathrm{C}$ for 4 days. After a single colony was purified, it was transferred to Gause's no. 1 culture for 4 days $[14,15,26]$. The serial number was preserved.

\section{Screening of antagonistic Actinomycetes}

The antimicrobial activity of the isolated actinomycetes was screened by double-layer agar method. After culturing for 5 days, actinomycetes were cut into pieces with a perforator $(\Phi=8 \mathrm{~mm})$ and moved to the center of Gause's no. 1 culture. They were then grown at $28^{\circ} \mathrm{C}$ for 2 days for colonization. Fusarium wilt of banana fungal pathogen was prepared for the fungi suspension $\left(6 \times 10^{8}\right.$ $\mathrm{CFU} / \mathrm{mL}$ ) with aseptic water and evenly sprayed on the plate with a 2-day culture of actinomycetes. Suspension was poured into $15 \mathrm{~mL}$ Nutrient Agar (NA) culture (the formula: $10.0 \mathrm{~g}$ protein, $3.0 \mathrm{~g}$ beef powder, $5.0 \mathrm{~g}$ sodium chloride and $15.0 \mathrm{~g}$ agar were dissolved in $1 \mathrm{~L}$ distilled water, $\mathrm{pH}$ was adjusted to 7.3 ) at $40^{\circ} \mathrm{C}$. Each treatment was repeated thrice. A plate without actinomycetes was used as the control. The diameter of the inhibition circle was measured at $28^{\circ} \mathrm{C}$ for $24 \mathrm{~h}$ [16, 23, 25-28].

\section{Inhibitory effect of antagonistic Actinomycetes on the growth of pathogenic Fungi and Bacteria}

Before the inhibitory experiment, the screened antagonistic actinomycete was cultured for 5 days, and pathogenic fungal cake was prepared by sterile culture $(\Phi=8 \mathrm{~mm})$. The fungi were placed at the center of a PDA flat $[14,15]$. After culturing for 2 days at $28^{\circ} \mathrm{C}$, five kinds of pathogenic fungal cakes were inoculated symmetrically $2 \mathrm{~cm}$ apart from both sides of the actinomycetes by using the same method. A fungal disc was placed in the center of the plate. A fungal mycelia disc alone in the center of the plate served as a control. The diameters of the inhibition zones were measured after incubation for 7 days at 
$28^{\circ} \mathrm{C}$. Each treatment was repeated thrice, and the width of the inhibition band was utilized to measure the inhibitory effect of this strain on pathogenic fungi. E. coli, S. aureus, and B. subtilis, were made into bacterial suspension $\left(1 \times 10^{8} \mathrm{cfu} / \mathrm{ml}\right)$ with sterile water. The paper soaked with actinomycetes was evenly placed in a $9 \mathrm{~cm}$ plate coated with $200 \mathrm{~mL}$ bacterial solution at $37{ }^{\circ} \mathrm{C}$ and cultured for $24 \mathrm{~h}$. The diameter of the bacteriostat was measured. Meanwhile, paper soaked in normal saline was used as the control. We aimed to analyze the inhibitory effect of the screened antagonistic actinomycete on pathogens and bacteria.

\section{Pot culture experiments}

Pot culture experiments were performed under greenhouse conditions, i.e., $28^{\circ} \mathrm{C}, 70 \%$ humidity, and sufficient natural light. The fermentation broth of actinomycete FS4 was inoculated in sterilized Gause's no. 1 culture and incubated with shaking $(150 \mathrm{rpm})$ at $28^{\circ} \mathrm{C}$ for 7 days. The fermentation broth was filtered then diluted 50 -fold, and $50 \mathrm{ml}$ of the liquid was inoculated into the banana seedlings to establish four treatment groups, as follows: CK1 (non-inoculated FOC.4 and application of sterile water); CK2 (inoculated FOC.4 and application of sterile water); CK3 (inoculated FOC.4 and polymycin); and A (inoculated FOC.4 and fermentation broth of actinomycete FS4). Banana seedlings with consistent growth rate of 5-6 leaves were selected and soaked in pathogen suspension at a concentration of $10^{7} \mathrm{cfu} / \mathrm{mL}$. Then, they were transplanted into a plastic bowl containing $700 \mathrm{~g}$ soil and filled with $50 \mathrm{~mL}$ pathogen suspension at the rhizosphere soil of banana seedlings. The banana seedlings were cultivated in a greenhouse. Each experiment was repeated thrice. The watering treatment liquid $\mathrm{A}$ and the positive control CK3 were applied to the roots of the banana seedlings. The control treatment of the wilt disease was water treated with water for several days. The disease index and the disease prevention effect of banana seedlings transplanted during 49 days were calculated by the following formula. The average fresh biomass and incidence of banana seedlings were determined on the 49th day.

\section{Classification and identification of strains Observation of morphological characteristics}

Sterilized glass was inserted into the Gause's no. 1 culture inoculated with actinomycetes at $45{ }^{\circ} \mathrm{C}$. Coverslips were taken out after incubation at $28^{\circ} \mathrm{C}$ for 21 days $[14,21$. Aerial hyphae, hypha, and spore characteristics were observed with a transmission electron microscope.

\section{Physiological and biochemical characteristics}

The target actinomycetes were cultured at $28^{\circ} \mathrm{C}$ for 21 days. The color of hyphae and airborne hyphae and the existence of soluble pigments were observed $[15,21]$.

\section{Phylogenetic characteristics}

Genomic DNA of FS-4 was isolated using the bacterial genomic DNA rapid extraction kit (Sigma-Aldrich Co., Ltd., USA) and the bacterial $16 \mathrm{~S}$ rDNA was amplified using the universal primers 27F (5'-AGAGTTTGATCCTGGCTCA G-3') and 1492R (5'-GGTTACCTTGTTACGACTT-3'). PCR amplifications were performed with a Trio PCR System (Biometra, Germany), in a total volume of $25 \mu \mathrm{l}$ consisting of template DNA $(2.0 \mu \mathrm{L}), 2 \times$ Taq PCR Master Mix $(12.5 \mu \mathrm{l}), \mathrm{dd}_{2} \mathrm{O}(8.5 \mu \mathrm{l})$, Upstream primer $(1 \mu \mathrm{L})$ and Downstream primer $(1 \mu \mathrm{L})$. The conditions for thermal cycling were as follows: denaturation of the DNA at $94^{\circ} \mathrm{C}$ for $5 \mathrm{~min}$; and $35 \mathrm{cy}$ cles at $94{ }^{\circ} \mathrm{C}$ for $30 \mathrm{~s}$, primer annealing $30 \mathrm{~s}$ at $55^{\circ} \mathrm{C}$ for template DNA, and DNA elongation at $72{ }^{\circ} \mathrm{C}$ for $90 \mathrm{~s}$.

PCRs were performed in the Trio PCR System (Biometra, Germany). The PCR system and conditions were as described by Himaman et al. [29]. The PCR amplification products were visualized by $1.0 \%(\mathrm{w} / \mathrm{v})$ agarose gel electrophoresis. The amplified PCR products were sequenced by a Sanger-based, automated sequencer (Applied Biosystems).

The product was purified and sequenced. GenBank was used to search for sequence similarity, and the sequence of the pattern strain with high similarity was selected. The homology was compared by using the neighbor-joining method in MEGA5.0. A phylogenetic tree was constructed to determine the taxonomic position of the actinomycetes $[19,22]$.

$$
\text { Disease index }=\frac{\sum(\text { number of diseased plants } \times \text { representative value })}{\text { the sum of the number of plants } \times \text { the representative value of the most serious disease }} \times 100 \%
$$

Disease prevention effect $(\%)=\frac{\text { control disease index-treatment of disease index }}{\text { control disease index }} \times 100 \%$ 
Optimization of the conditions for improving the bacteriostatic activity of the Actinomycete FS-4 fermentation broth

After cultivation in Gause's no. 1 culture at $37^{\circ} \mathrm{C}$ at 120 $\mathrm{r} / \mathrm{min}$, precipitation for $24 \mathrm{~h}$ at $4{ }^{\circ} \mathrm{C}$, and autoclaving at $121^{\circ} \mathrm{C}$ and $0.1 \mathrm{MPa}$, treatment with actinomycetes $F S-4$ antagonistic bacterial fermentation broth was performed for $20 \mathrm{~min}$.

\section{Effects of Different Carbon and Nitrogen Sources}

Under the same culture conditions, $2 \%$ glucose, saccharose, soluble starch, corn flour, and lactose were used to replace the soluble starch in the basic fermentation culture. Then, $0.1 \%$ of ammonium sulfate, monarkite, nitrate potash, yeast powder, and peptone instead of $\mathrm{KNO}_{3}$ were respectively added to the basic fermentation culture. The best carbon and nitrogen sources were determined thrice according to the method described in Section 2.4.

\section{Effect of Inorganic Salt Content}

The concentrations of sodium chloride, potassium hydrogen phosphate, and magnesium sulfate were set at $0.025,0.050,0.075,0.100$, and $0.125 \%$. The best inorganic salt content was determined thrice according to the method described in the section on the screening of indicator strains.

\section{Effects of Initial $p H$, Fermentation Temperature, and Time} The initial $\mathrm{pH}$ of the culture was set at 5-9, temperature was set at $22^{\circ} \mathrm{C}-34{ }^{\circ} \mathrm{C}$, and time was at $48-144 \mathrm{~h}$. The optimum initial $\mathrm{pH}$ value, fermentation temperature, and time were determined thrice according to the method described in the section on the screening of indicator strains.

\section{Optimization of fermentation conditions by response surface analysis}

On the basis of the single-factor experiment, sucrose, peptone, and fermentation time were selected as the investigation factors, and response surface analysis was carried out according to the method described in the section on the screening of indicator strains.

\section{Statistical analysis}

Design-Expert V8.0.6 software was used to design the Box-Behnken experiment. All the experiments were repeated thrice, and ANOVA was carried out by SPSS 19.0.

\section{Results}

Isolation and screened of Actinomycetes

The strains isolated from soil samples were screened in accordance with the colony morphology and color similarity on the purified culture, and the corresponding actinomycetes were obtained. After preliminary screening by
Table 1 Inhibitory effects of strain FS-4 against three bacterial strains

\begin{tabular}{llll}
\hline Bacterial strain & $\begin{array}{l}\text { Escherichia } \\
\text { coli }\end{array}$ & $\begin{array}{l}\text { Bacillus } \\
\text { subtilis }\end{array}$ & $\begin{array}{l}\text { Staphylococcus } \\
\text { aureus }\end{array}$ \\
\hline $\begin{array}{l}\text { Bacteriostasis } \\
\text { band width (mm) }\end{array}$ & $12.5 \pm 0.5$ & $16.5 \pm 0.8$ & - \\
\hline
\end{tabular}

plate confrontation culture method and re-screening by the oxford cup method, one of the largest actinomycetes produced in the inhibition zone was identified as FS-4. By combining traditional taxonomy with $16 \mathrm{~S}$ rRNA gene sequence, the preliminary identification of Streptomyces ma. FS-4 achieved the maximum sequence similarity with Streptomyces. ma, reaching 99\%. The phylogenetic tree created based on sequence indicated that the strains were in the same family.

\section{Antimicrobial activity evaluation of strain FS-4}

The inhibitory effect of strain FS-4 fermentation products on three kinds of bacterial was shown in Table 1 . The fermentation products have no inhibitory effect on S. aureus and had better inhibitory effect on B. subtilis than E. coli. Therefore, Bacillus subtilis was selected as the indicator bacterium for the next study.

Strain FS-4 exerted some inhibitory effects on Fusarium oxysporum f. sp. cubense Race1 (FOC.1), F. oxysporum f. sp. cubense Race 4 (FOC.4), Curvulatia fallaxis (CFO), Colletotrichum gloeosporides (CG), and Alternaria tenuissima Maa (MAA) (Table 2). The antagonism to CG was the strongest.

When the plants were inoculated with pathogen at a high concentration of FOC. $4\left(1 \times 10^{7} \mathrm{cfu} / \mathrm{mL}\right)$ for 7 days, the blight rapidly spread. The disease began to appear in group A at 7 days after treatment, and it appeared in the positive control group CK3 group at 10 days. Small plants continued to die over time. In the final group A, the disease index was $16 \%$. In the CK3 group, the disease index was $8 \%$. Although group A did not achieve the same effect as the CK3 group compared with the control, the number of dead plants was greatly reduced, and the disease prevention effect was $78.95 \%$ (Fig. 1). After field application comparison, group A showed good yield

Table 2 Inhibitory effect of strain FS-4 against five plant pathogenic fungal strains

\begin{tabular}{ll}
\hline Fungus & Bacteriostasis band width $(\mathrm{mm})$ \\
\hline FOC.1 & $10.07 \pm 0.34 \mathrm{~b}$ \\
FOC.4s & $12.12 \pm 0.56 \mathrm{a}$ \\
CFO & $12.26 \pm 0.87 \mathrm{ab}$ \\
MAA & $9.11 \pm 0.34 \mathrm{~b}$ \\
CG & $13.61 \pm 0.79 \mathrm{bc}$
\end{tabular}

Note: Small-case letters represent $5 \%$ significant level 


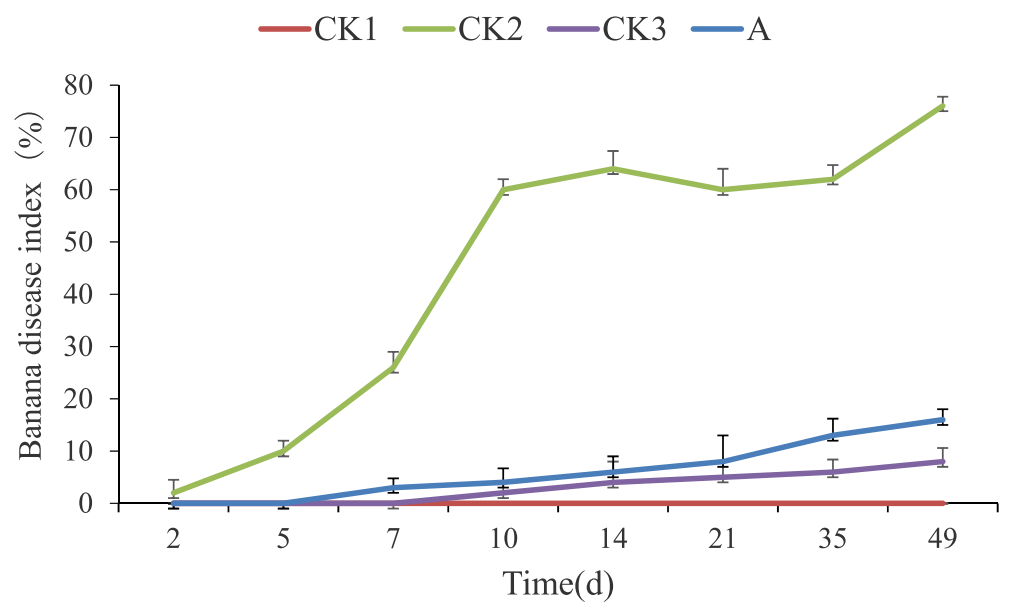

Fig. 1 Effect of Streptomyces ma. FS-4 on banana Fusarium wilt

in the field infected with wilt disease; such yield was similar to the yield of bananas in the completely healthy group CK1. The incidence rate was still higher than CK3 but much lower than CK2. Comprehensive comparison showed that the incidence rate of group A was low, the effect of disease prevention was good, and the yield on the field was excellent (Fig. 2).

\section{Classic taxonomic features}

The antagonistic actinomycetes were cultured using the insertion method. The results of transmission electron microscopy showed that the filaments of strain FS-4 were straight and flexible, and the spores were oval (Fig. 3). The strain FS-4 grew well on seven kinds of cultures. The colony morphology was shown in Additional file 1: Table S1. The aerial mycelium was mainly white and gray white, and the glycerol asparagine agar (ISP7) culture was bean yellow in color. The mycelium in the base strain was rich in color in different cultures, and no soluble pigment was produced.

The FS-4 actinomycete can do the following: reduce nitrate; hydrolyze starch; and produce $\mathrm{H}_{2} \mathrm{~S}$, melanin, urease, and tyrosinase. However, it cannot liquefy gelatin and milk peptone and did not exhibit solidification. The $\mathrm{pH}$ range of growth was 5.0-10.0, and the optimum $\mathrm{pH}$ for growth was 7.0. The optimum growth temperature was $28^{\circ} \mathrm{C}-$ $32^{\circ} \mathrm{C}$. It did not grow on culture with $\mathrm{NaCl}$ content greater than $3 \%$. Other physiological and biochemical characteristics are shown in Additional file 2: Table S2.

\section{Phylogenetic characteristics}

According to Fig. 4, the strain FS-4 and Streptomyces ma. were clustered in the same branch and had high similarity in sequence with a similarity coefficient of 99\%. The target strain was identified as Streptomyces

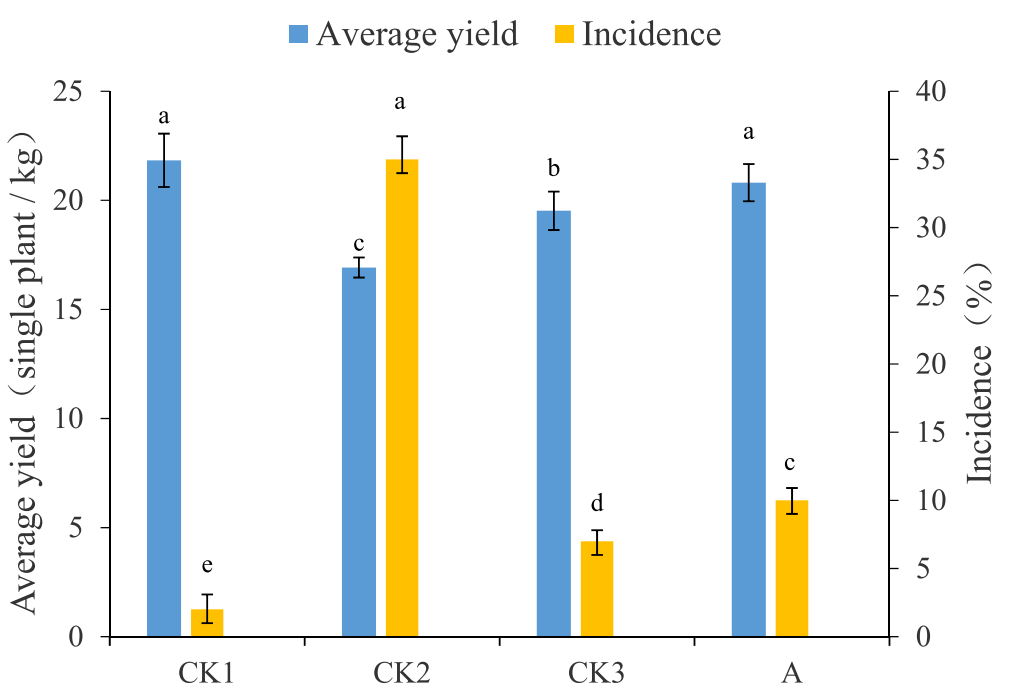

Fig. 2 Effect of Streptomyces ma. FS-4 on banana average yield and disease incidence. Note: Different lowercase letters show significant difference at $P<0.05$ 


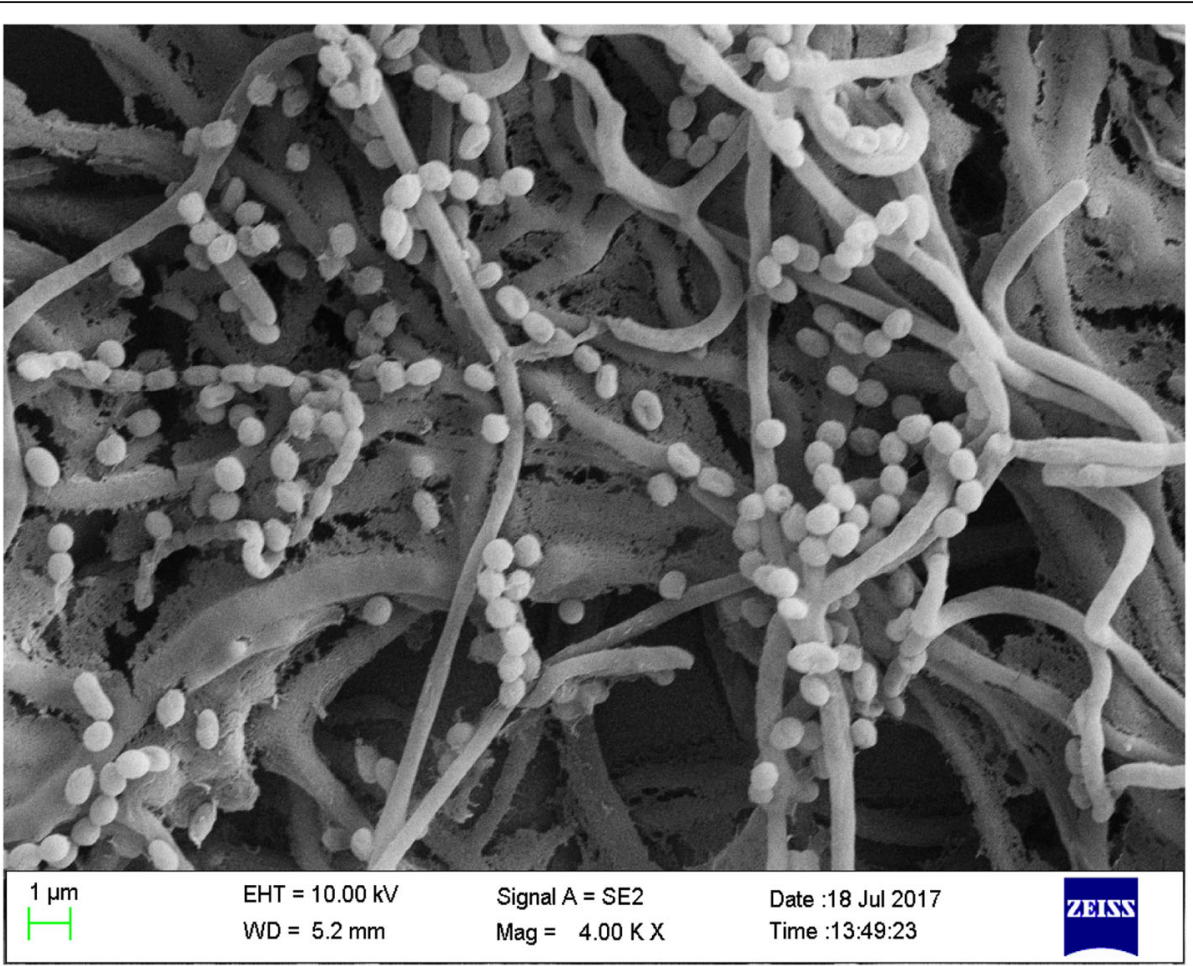

Fig. 3 Morphological characteristics of spore chain and spore of strain XL-6 (4.00 KX)

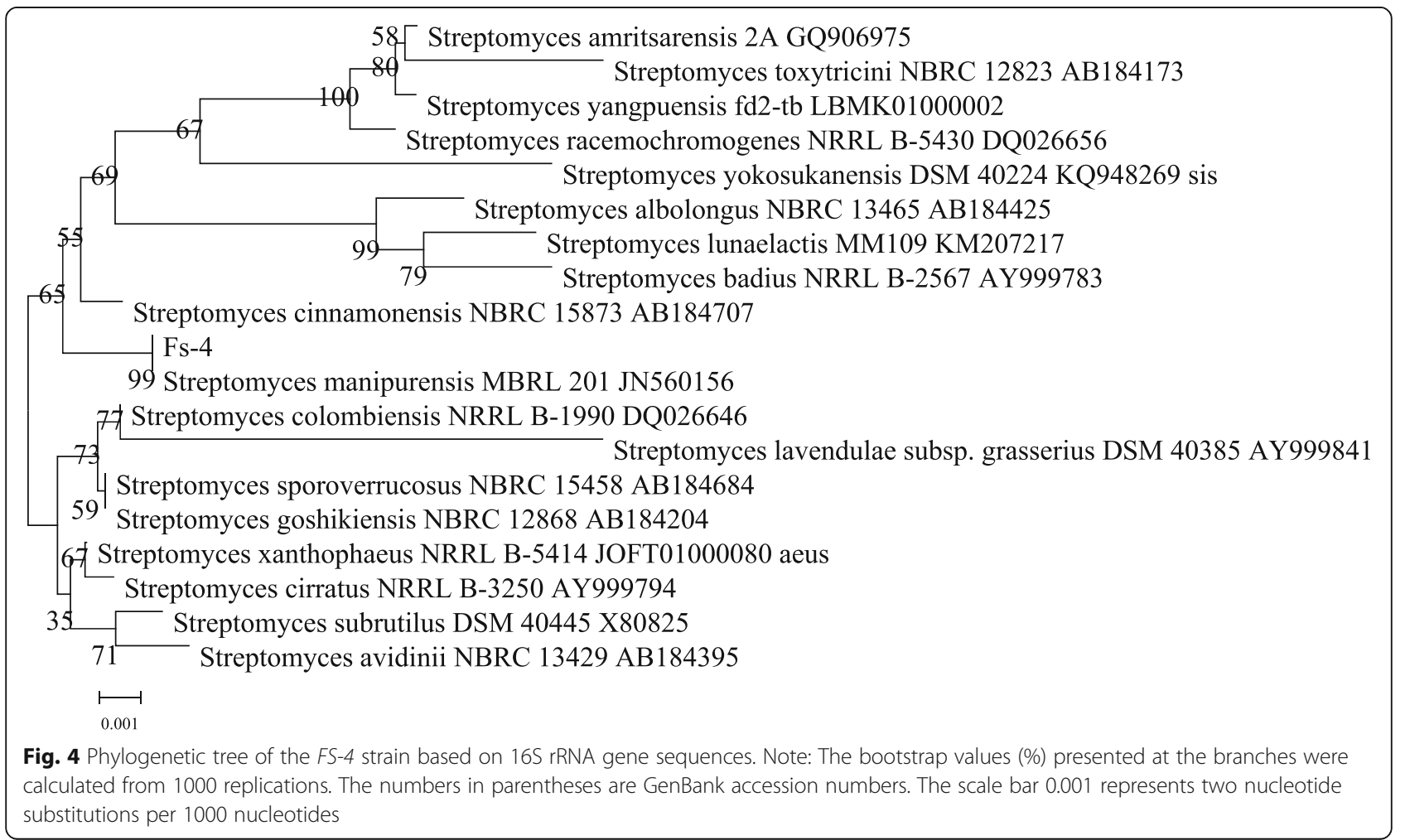


ma, according to the following: results of cell morphology; culture; physiological and biochemical characteristics of the strain FS-4; and phylogenetic analysis based on the $16 \mathrm{~s}$ rRNA.

\section{Optimization of fermentation conditions on Bacteriostasis of the Streptomyces ma.FS-4 \\ Carbon source and content}

The carbon source was optimized on the basis of Gause's no. 1 culture. Saccharose, lactose, corn flour, glucose, and soluble starch were used as carbon sources. As shown in Fig. 5a, the maximum diameter of the inhibition circle of fermentation broth reached $20.5 \mathrm{~mm}$ on the culture with sucrose as carbon source. Saccharose was the most favorable carbon source for the Streptomyces ma. FS-4 to produce bacteriostatic substances. By adjusting saccharose at $1-5 \%$, the optimal carbon source concentration was achieved. As shown in Fig. 5b, when the sucrose content was $2 \%$, the fermentation broth had the largest bacteriostasis circle and the highest number of antimicrobial substance.

\section{Nitrogen source and content}

The nitrogen source was optimized on the basis of Gause's no. 1 culture. As shown in Fig. 6a, the culture with peptone was the best nitrogen source with a diameter of $24 \mathrm{~mm}$. When the peptone content was $0.2 \%$, the fermentation broth had the largest inhibition circle and the highest number of antimicrobial substances (Fig. 6b).

\section{Inorganic salt concentration}

The concentration of inorganic salt was optimized on the basis of Gause's no. 1 culture, as shown in Fig. 7. The
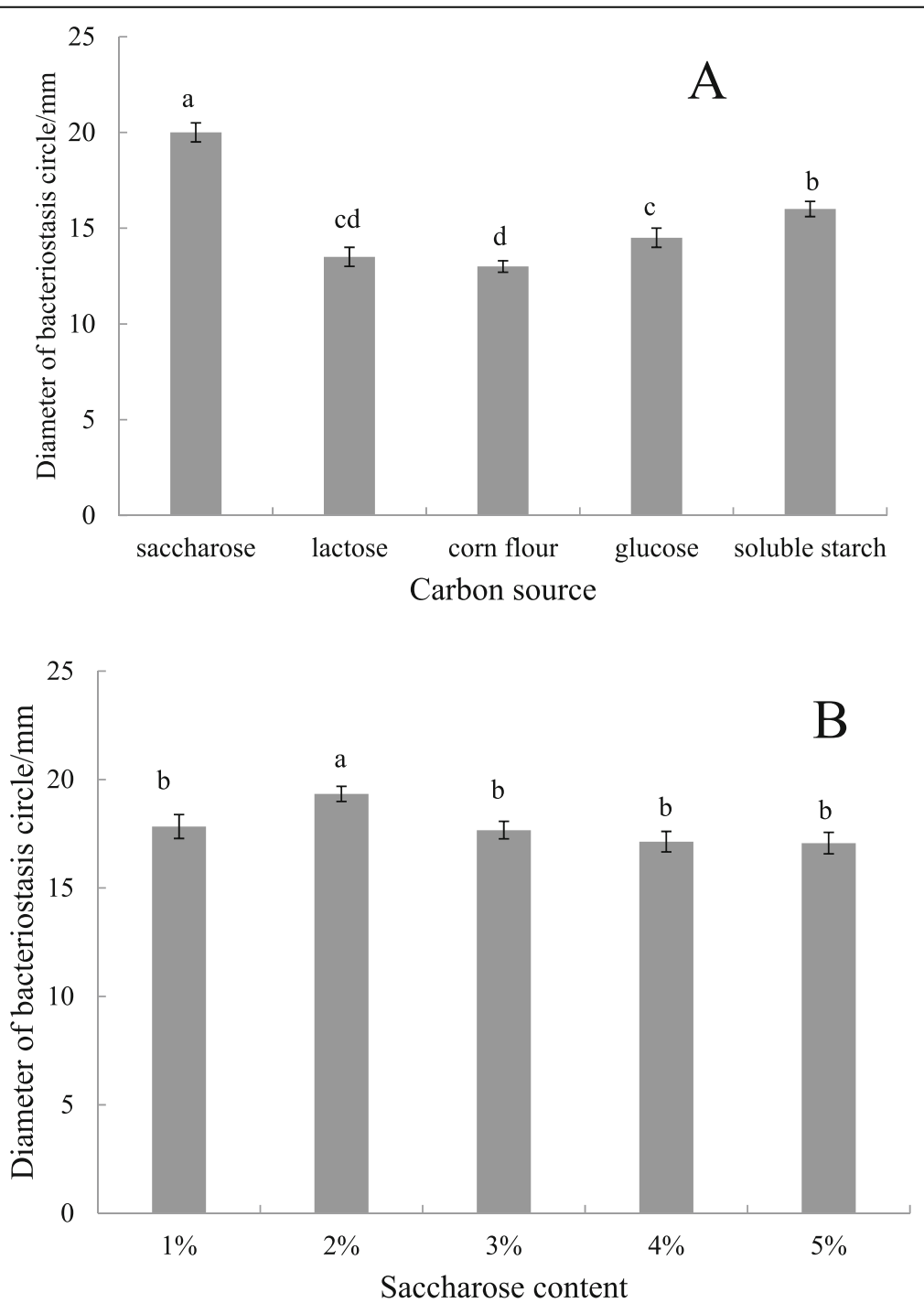

Fig. 5 Effect of carbon sources on the activity of antimicrobial substance produced by the F-4 strain. Note: $\mathbf{A}$ (carbon type), B (Saccharose content), Different lowercase letters show significant difference at $P<0.05$ 

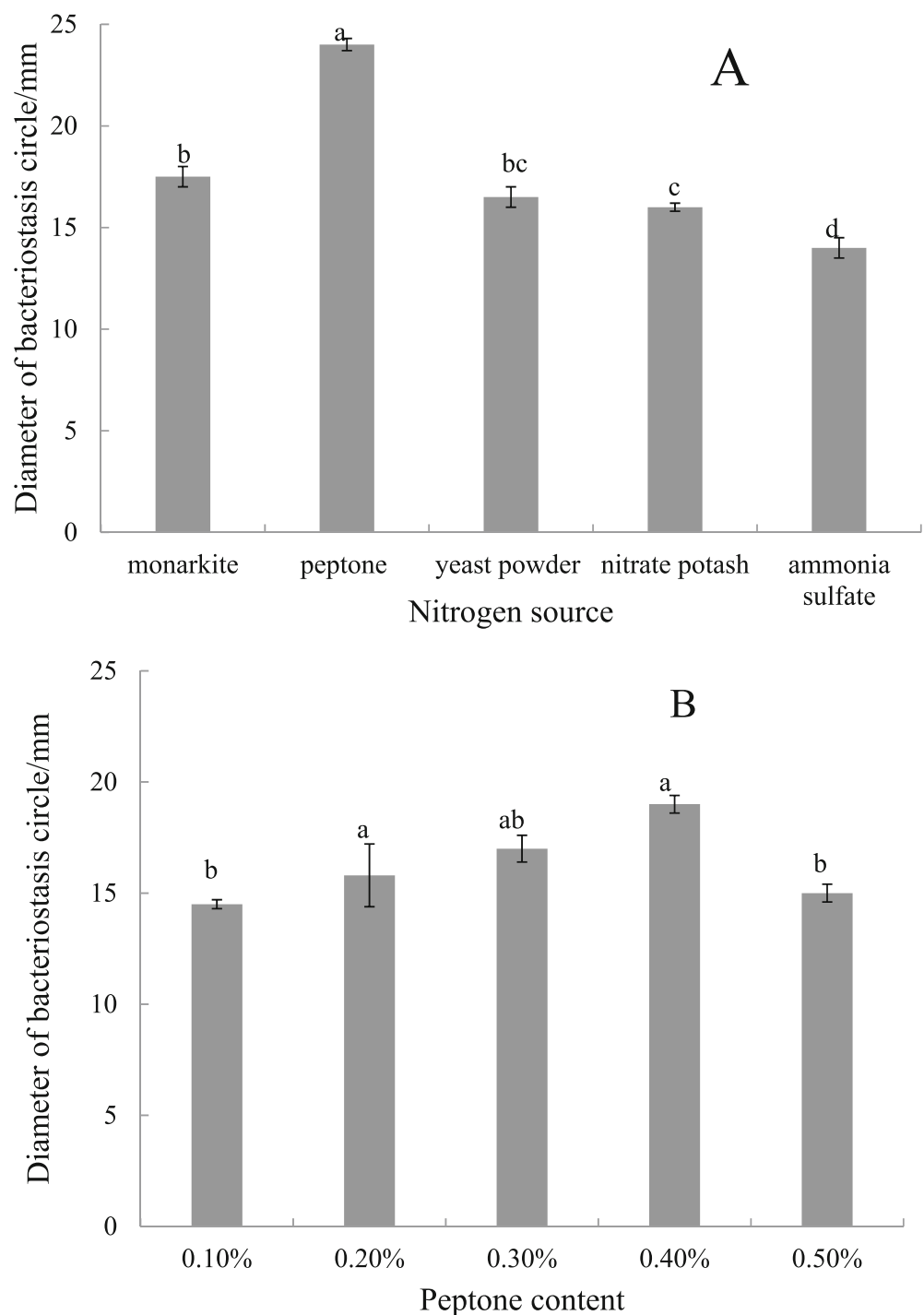

Fig. 6 Effect of carbon sources on activity of antimicrobial substance produced by the FS-4 strain. Note: A (nitrogen type), B (Saccharose content), Different lowercase letters show significant difference at $P<0.05$

regulation of three kinds of inorganic salt concentrations had little effect on antibacterial substances produced by the Streptomyces ma.FS-4.

\section{Different culture conditions}

Appropriate $\mathrm{pH}$ value, fermentation temperature, and time contributed to the production of antimicrobial substances by Streptomyces ma. FS-4. Figure 8a shows that the diameter of the bacteriostasis circle varied slightly at $\mathrm{pH} 6$ to 8 . When the $\mathrm{pH}$ was 7 , the maximum diameter of the bacteriostasis circle was $19 \mathrm{~mm}$. When the temperature was $22^{\circ} \mathrm{C}-31{ }^{\circ} \mathrm{C}$, the diameter of the bacteriostasis circle changed slightly. However, when the temperature was $28^{\circ} \mathrm{C}$, the bacteriostasis circle had the largest diameter (Fig. 8b). The diameter of the bacteriostasis circle reflected the number of antimicrobial substances in the fermentation broth for $24 \mathrm{~h}$. The diameter of the bacteriostasis circle no longer increased after $48 \mathrm{~h}$ of fermentation. Streptomyces ma. FS-4 basically stopped producing antimicrobial substances or the activity of antimicrobial substances decreased (Fig. 8c).

\section{Analysis and optimization of response surface}

The results of response surface experiments were fitted with multivariate regression. The quadratic regression equation between the diameter of inhibition circle and peptone concentration, sucrose concentration, and time were as follows: $\mathrm{Y}=25.26+1.94 \mathrm{~A}+0.31 \mathrm{~B}+1.63 \mathrm{C}$ $-0.25 \mathrm{AB}+0.88 \mathrm{AC}+0.38 \mathrm{BC}-0.88 \mathrm{~A}^{2}-0.38 \mathrm{~B}^{2}-$ $2.26 \mathrm{C}^{2}$. The ANOVA for the regression equation model is presented in Additional file 3: Table S3. 


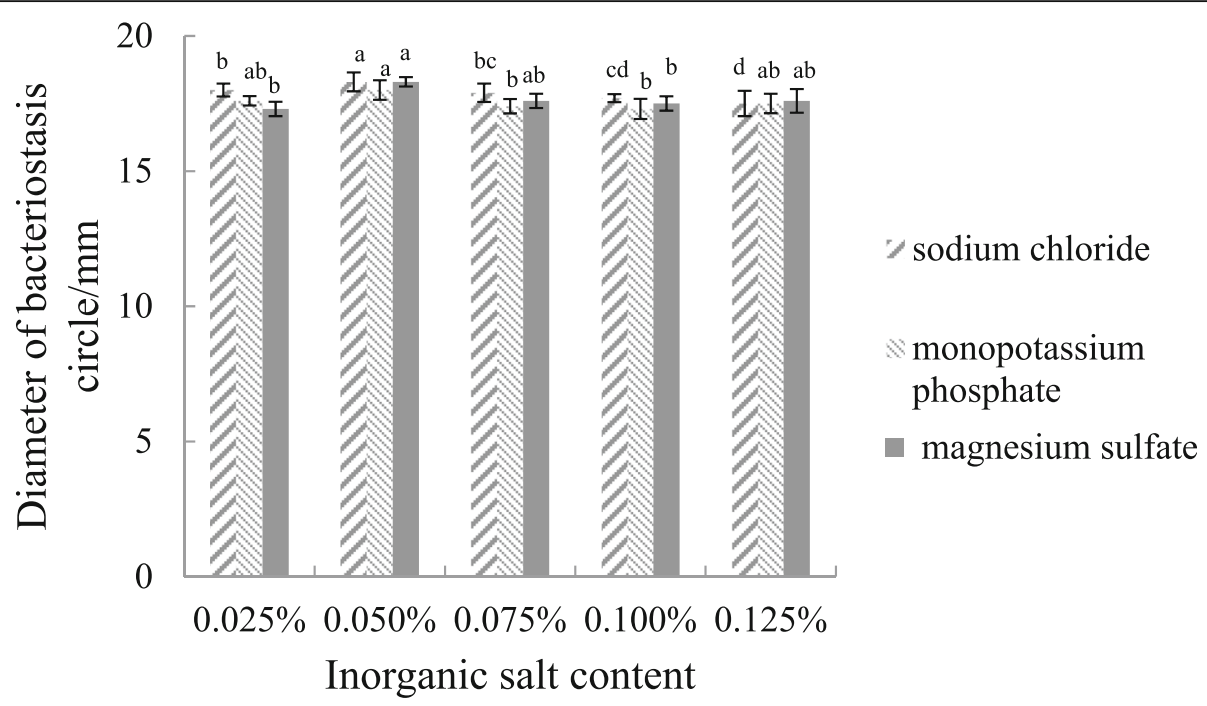

Fig. 7 Effect of inorganic salt content on the activity of antimicrobial substance produced by the FS-4 strain. Note: Different lowercase letters show significant difference at $P<0.05$

The graph of response surface analysis can intuitively reveal the influence of the variables and their interactions on the response value. The response surface obtained from the regression model is shown in Additional file 5: Figure S1.

Additional file 4: Table S4 showed that the regression equation model was very significant, thereby indicating that the model was reliable. The correction coefficient of the model was 0.9094 , thereby showing that the fitting model was good. The influence on the diameter of bacteriostasis was in the following order: peptone $>$ saccharose $>$ time.

The optimum conditions were obtained by DesignExpert V8.0.6 software: $0.5 \%$ peptone, $2.37 \%$ sucrose, and time $62.04 \mathrm{~h}$. Under this condition, the theoretical value of the bacteriostasis circle diameter was $27.06 \mathrm{~mm}$. To facilitate the experimental operation, the conditions were revised as follows: peptone concentration $0.5 \%$, sucrose concentration $2.4 \%$, and time $62 \mathrm{~h}$. The diameter of the bacteriostasis circle was $26.7 \mathrm{~mm}$, which was close to the predicted theoretical value.

\section{Discussion}

Fusarium wilt of banana is a devastating disease in banana planting. From the viewpoint of soil microbial diversity, the growth and reproduction of pathogenic fungi can be effectively controlled only by increasing the diversity of antagonistic microorganisms in soil $[5,6,9]$. Actinomycetes are abundant bioactive material resources. They can produce antibacterial substances, degrade the cell wall and enzymes of fungi, and are a kind of microbial population with great practical value [19, 24, 25]. In this study, stable and antagonistic actinomycetes were isolated from banana rhizosphere soils that infested with severe Fusarium wilt disease. The strain was named
Streptomyces ma. FS-4. Biological organic fertilizer was made from the fermentation broth of actinomycetes $F S$ 4 and used for the biological control of banana wilt. The disease was controlled from the point of view of microecology. Actinomycete FS-4 fermentation broth showed good control effect on infected banana seedlings, thereby reducing their disease index and improving the prevention and control effects of banana plant wilt. Compared with the control, the prevention and control effects of actinomycete $F S$ - 4 fermentation broth was significant; the disease prevention effect reached $78.95 \%$, and the disease index was only $16 \%$. Thangavelu et al. [30] isolated Bacillus subtilis from banana root soil, and the control effect of Fusarium wilt of banana can reach $41 \%$. Nel et al. [31] screened out strains CAV255 and CAV241 from antibacterial bacteria, whose disease-prevention capacities for Fusarium wilt of banana were 87.4 and $75 \%$, respectively. Therefore, actinomycete FS-4 fermentation broth can be used in production and field protection.

The spores of strain FS-4 were oval, compared with $S$. manipurensis PH2494 [21], Streptomyces spectabilis $\mathrm{PH} 2792$ [24], and S. spectabilis B4491 [14]. All of these species can hydrolyze starch and produce $\mathrm{H}_{2} \mathrm{~S}$ ad brown pigment. However, PH2792 and PH2494 can liquefy gelatin and reduce nitrate, but B4491 cannot. Moreover, strain FS-4 can reduce nitrate but cannot liquefy gelatin. In terms of carbon usage, all can utilize glucose, fructose, mannitol, galactose, and soluble starch. However, PH2792 cannot use sucrose; PH2494 cannot use sucrose; B4491 cannot use arabinose, xylose, inositol, chrysanthemum, and sorbitol; and strain FS-4 cannot use sucrose, trehalose, and inositol. In terms of culture characteristics, strain FS-4 was highly similar to the other three Streptomyces strains. The main hyphae were white and grey 

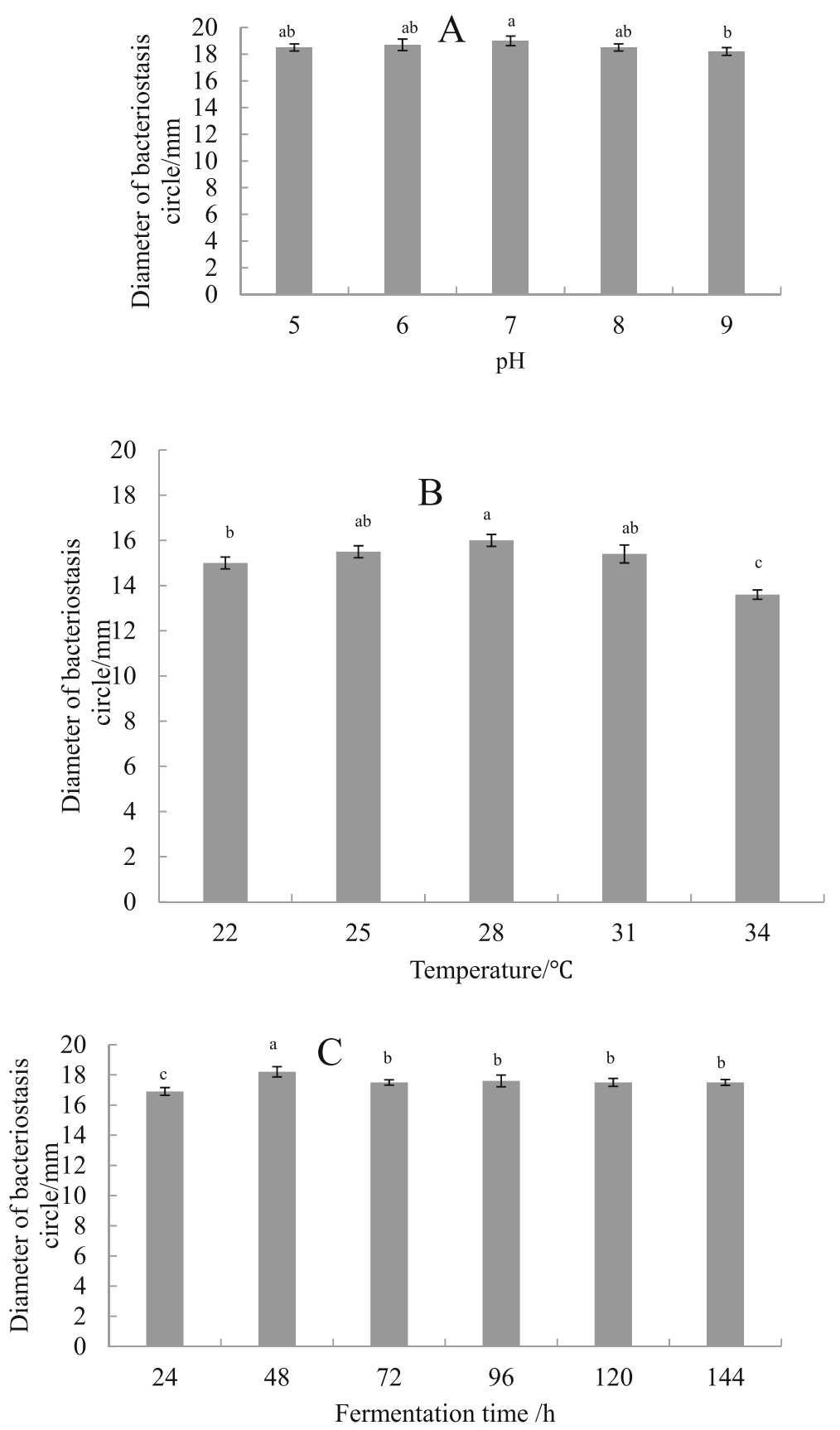

Fig. 8 Effect of different conditions on the inhibition activity of the submerged and cultured FS-4. Note: A (pH) , B (temperature ), C (fermentation time), Different lowercase letters show significant difference at $P<0.05$

white, and the inner hyphae were orange powder to orange red. The difference between strain FS-4 and the three other Streptomyces strains was that strain $F S$ - 4 had a root-like inner hyphae, and its main hyphae consisted of a polybranch. The spore silk of strain FS4 was also long, straight, and gently curved. Strain FS4 was further identified as S. manipurensis.

S. manipurensis can produce various antibiotics with high bacteriostatic activity, thereby showing its high application value in medicine. However, few researchers have studied the biological control effect of S. manipurensis on plant diseases $[19,21]$. Through the study of antagonistic actinomycete $F S-4$ broad-spectrum resistance, researchers found that this strain exerted a good inhibitory effect on soil-borne pathogens, such as F. oxysporum f. sp. cubense and A. tenuissima [14, 17]. However, field and plant microecological environment influence the bacteriostatic effect of actinomycete $F S-4[19,22]$. Accordingly, to improve the use of 
actinomycete $F S$-4 in actual production, follow-up studies on the separation and identification of antiseptic active substances in the fermentation solution are required. Such studies should explore the mechanism of antiseptic bacteria and field-protective effects. Antifungal-compound production also has the crucial effect of inhibiting soilborne fungal pathogens. Ling et al. [32] reported that interactions between beneficial microbe and the fungal pathogen have evolved to enable efficient antibiotic production and survival in the environment.

Antimicrobial active substance is typically used as the base on which antagonistic actinomycetes exert biological effect. The yield of antimicrobial active substance determines the actual effect of bacteriostasis [13, 20, 25]. Fermentation is the basis for obtaining numerous microbial active metabolites. The type and yield of microbial metabolites are closely related to their culture conditions, such as carbon source in culture and $\mathrm{pH}$ value of nitrogen source $[19,21,24]$. Carbon source is the energy source for microbial metabolism, and the selection of suitable carbon source can increase the rate of microbial reproduction and metabolite production [14, 15]. Nitrogen is an important element for nucleic acid and protein, which are the raw materials synthesized by microorganisms to create cellular metabolites $[15,21,25]$. The $\mathrm{pH}$ affects the ability of bacteria to absorb nutrients and produce active substances. Fermentation temperature affects the growth of microorganisms and the production of secondary metabolites; time affects the production and activity of secondary metabolites $[18,20]$. Therefore, exploring suitable culture conditions is important. In this study, the fermentation conditions of Streptomyces ma. FS-4 were optimized by single factor and response surface test. The nutrient base formula and culture conditions of fermentation were obtained; these were suitable for the production of antimicrobial active substances by the target strains. The bacteriostatic activity of the optimized fermentation broth was significantly higher $(P<0.05)$ than that of the basic fermentation culture. The maximum bacterial ring diameter of optimized fermentation solution for Bacillus subtilis was $26.7 \mathrm{~mm}$, whereas that of the basic fermentation culture was 23.7 $\mathrm{mm}$, which was an increase of $12.65 \%$.

Microbial fermentation is a dynamic biological process. The $\mathrm{pH}$, oxygen capacity, and product quantity of various nutrient contents in the culture are constantly changed, and various different factors exert a great effect on the types and yield of fermentation products $[15,17,20]$. In this study, only the state of culture and culture conditions before fermentation were considered, and the factors of fermentation process were not monitored dynamically.

\section{Conclusions}

Actinomycete FS-4 could serve as a biological control to inhibit five pathogenic fungi and promote banana growth.
Pot experiments showed that the incidence of banana seedlings was reduced after using Streptomyces ma. FS-4 treatment. The optimum fermentation conditions were tested, and the diameter of the inhibition circle was found to be $26.7 \mathrm{~mm}$. Combined with morphological observation, physiological and biochemical determination, and the phylogenetic method, strain FS-4 was identified as Streptomyces ma.

\section{Supplementary information}

Supplementary information accompanies this paper at https://doi.org/10. 1186/s12866-019-1688-z.

Additional file 1: Table S1. Medium characteristics of strain FS-4.

Additional file 2: Table S2. Physiological and biochemical characteristics of strain FS-4.

Additional file 3: Table S3. Results of response surface design experiments.

Additional file 4: Table S4. ANOVA for regression equation model. Additional file 5: Figure S1. Effect of various factors on activity of antimicrobial substance produced by FS-4.

\section{Abbreviations}

ma: manipurensis; PDA: Potato Dextrose Agar

\section{Acknowledgements \\ Not Applicable}

\section{Authors' contributions}

YD and WH designed the research. $\mathrm{HH}$ and JX supervised the research work and guided the experimental design. ZP and JingjingC provided the suggestion of the research work. JianC prepared the manuscript. All authors contributed to interpretation of the results and manuscript drafting. All authors read and approved the final manuscript.

\section{Funding}

This work was supported by "Modern Agro-industry Technology Research System (CARS-31-16)" and Modern Agro-talent support plan. Funding body provided approval for the manuscript and had no role in design of the study, analysis and interpretation of data.

\section{Availability of data and materials}

All data generated or analyzed in this study are presented within this manuscript. All materials used in this study including raw data shall be available upon reasonable request.

Ethics approval and consent to participate Not applicable.

Consent for publication

Not applicable.

\section{Competing interests}

The authors declare that they have no competing interests.

\section{Author details}

'Key Laboratory of Tropical Fruit Biology, Ministry of Agriculture, Chinese Academy of Tropical Agricultural Science, South Subtropical Crop Research Institute, Zhanjiang 524091, China. ${ }^{2}$ College of Food Science and

Technology, Hainan University, Haikou 570228, China. 
Received: 23 November 2018 Accepted: 17 December 2019

Published online: 31 January 2020

\section{References}

1. Shen Z, Ruan Y, Chao X, Zhang J, Li R, Shen Q. Rhizosphere microbial community manipulated by 2 years of consecutive biofertilizer application associated with banana Fusarium wilt disease suppression. Biol Fertil Soils. 2015;51(5):553-62.

2. Guo L, Yang L, Liang C, Wang J, Liu L, Huang J. The G-protein subunits FGA2 and FGB1 play distinct roles in development and pathogenicity in the banana fungal pathogen fusarium oxysporum f. sp cubense. Physiol Mol Plant Pathol. 2016;93:29-38.

3. Han D, Wang L, Luo Y. Isolation, identification, and the growth promoting effects of two antagonistic actinomycete strains from the rhizosphere of Mikania micrantha Kunth. Microbiol Res. 2018;208:1-11.

4. Shen Z, Ruan Y, Wang B, Zhong S, Su L, Li R, Shen Q. Effect of biofertilizer for suppressing Fusarium wilt disease of banana as well as enhancing microbial and chemical properties of soil under greenhouse trial. Appl Soil Ecol. 2015;93:111-9.

5. Tan D, Fu L, Han B, Sun X, Zheng P, Zhang J. Identification of an endophytic antifungal bacterial strain isolated from the rubber tree and its application in the biological control of banana fusarium wilt. PLoS One. 2015;10(7): e0131974.

6. Karangwa P, Blomme G, Beed F, Niyongere C, Viljoen A. The distribution and incidence of banana Fusarium wilt in subsistence farming systems in east and Central Africa. Crop Prot. 2016:84:132-40.

7. Sharma P, Kalita MC, Thakur D. Broad spectrum antimicrobial activity of forestderived soil Actinomycete, Nocardia sp PB-52. Front Microbiol. 2016;7:347.

8. Song S, Chen X, Huang D, Xu Y, Zeng H, Hu X, Xu B, Jin Z, Wang W. Identification of miRNAs differentially expressed in fusarium wilt-resistant and susceptible banana varieties. S Afr J Bot. 2016;106:244-9.

9. Wang Y, Xia Q, Wang G, Zhang H, Lu X, Sun J, Zhang X. Differential gene expression in banana roots in response to fusarium wilt. Can J Plant Pathol. 2017;39(2):163-75.

10. Wang B, Shen Z, Zhang F, Waseem R, Yuan J, Huang R, Ruan Y, Li R, Shen Q. Bacillus amyloliquefaciens strain W19 can promote growth and yield and suppress Fusarium wilt in banana under greenhouse and field conditions. Pedosphere. 2016;26(5):733-44.

11. Wu Y, Fan W, Li X, Chen H, Takac T, Samajova O, Fabrice MR, Xie L, Ma J, Samaj J, et al. Expression and distribution of extensins and AGPs in susceptible and resistant banana cultivars in response to wounding and Fusarium oxysporum. Sci Rep. 2017;7:42400.

12. Chen YF, Zhou DB, Qi DF, Gao Z, Xie JH, Luo YP. Growth promotion and disease suppression ability of a Streptomyces sp CB-75 from banana rhizosphere soil. Front Microbiol. 2018,8:2704.

13. Dávila Medina MD, Gallegos Morales G, Hernández Castillo FD, Ochoa Fuente YM, Flores OA. Actinomicetos antagónicos contra hongos fitopatógenos de importancia agrícola. Rev Mex Cienc Agrícolas. 2013;4(8): 1187-96.

14. Mingma R, Pathom-aree W, Trakulnaleamsai S, Thamchaipenet A, Duangmal K. Isolation of rhizospheric and roots endophytic actinomycetes from Leguminosae plant and their activities to inhibit soybean pathogen, Xanthomonas campestris pv. Glycine. World J Microbiol Biotechnol. 2014; 30(1):271-80.

15. Jose PA, Jebakumar SRD. Phylogenetic appraisal of antagonistic, slow growing actinomycetes isolated from hypersaline inland solar salterns at Sambhar salt Lake, India. Front Microbiol. 2013:4:190.

16. Keikha N, Mousavi SAA, Nakhaei AR, Yadegari MH, Bonjar GHS, Amiri S. In vitro evaluation of enzymatic and antifungal activities of soil-Actinomycetes isolates and their molecular identification by PCR. Jundishapur J Microbiol. 2015;8(5):e14874.

17. Suksaard P, Pathom-aree W, Duangmal K. Diversity and plant growth promoting activities of actinomycetes from mangroves. Chiang Mai J Sci. 2017:44(4):1210-23.

18. Leon J, Jose Aponte J, Cuadra DL, Galindo N, Jaramillo L, Vallejo M, Marguet E. Extracellular enzymes production and pathogen inhibitory activity of actinomycetes isolated from Argopecten purpuratus. Rev Biol Marina Y Oceanografia. 2016;51(1):69-80

19. Wang D-s, H-k R, Erihemu ZZY. Isolation, identification and antagonistic activity evaluation of actinomycetes in barks of nine trees. Arch Biol Sci. 2017;69(2):345-51.
20. Pageni BB, Lupwayi NZ, Akter Z, Larney FJ, Kawchuk LM, Gan Y. Plant growth-promoting and phytopathogen-antagonistic properties of bacterial endophytes from potato (Solanum tuberosum L.) cropping systems. Can J Plant Sci. 2014;94(5):835-44.

21. Passari AK, Mishra VK, Gupta VK, Yadav MK, Saikia R, Singh BP. In vitro and in vivo plant growth promoting activities and DNA fingerprinting of antagonistic endophytic Actinomycetes Associates with Medicinal Plants. PLoS One. 2015;10(9).

22. Singh SP, Gaur R. Evaluation of antagonistic and plant growth promoting activities of chitinolytic endophytic actinomycetes associated with medicinal plants against Sclerotium rolfsii in chickpea. J Appl Microbiol. 2016;121(2):506-18.

23. Su LX, Shen ZZ, Ruan YZ, Tao CY, Chao YF, Li R, Shen QR. Isolation of antagonistic endophytes from banana roots against meloidogyne javanica and their effects on soil nematode community. Front Microbiol. 2017;8:2070

24. Xue L, Xue QH, Chen Q, Lin CF, Shen GH, Zhao J. Isolation and evaluation of rhizosphere actinomycetes with potential application for biocontrol of Verticillium wilt of cotton. Crop Protection. 2013;43:231-40.

25. Roy RN, Laskar S, Sen SK. Dibutyl phthalate, the bioactive compound produced by Streptomyces albidoflavus 321.2[J]. Microbiol Res. 2006; 161(2):121-6.

26. Abidin ZAZ, Malek NA, Zainuddin Z, Chowdhury AJK. Selective isolation and antagonistic activity of actinomycetes from mangrove forest of Pahang, Malaysia. Front Life Sci. 2016;9(1):24-31.

27. He L, Liu Y, Mustapha A, Lin M. Antifungal activity of zinc oxide nanoparticles against botrytis cinerea and penicillium expansum. Microbiol Res. 2011;166(3):207-15.

28. Dananjaya SHS, Udayangani RMC, Shin SY, Edussuriya M, Nikapitiya C, Lee J, De Zoysa M. In vitro and in vivo antifungal efficacy of plant based lawsone against fusarium oxysporum species complex. Microbiol Res. 2017;201:21-9.

29. Himaman W, Thamchaipenet A, Pathom-aree W, Duangmal K. Actinomycetes from eucalyptus and their biological activities for controlling eucalyptus leaf and shoot blight. Microbiol Res. 2016;188-189:42-52.

30. Thandavelu R, Palaniswam IA, Velazhahan R. Mass production of Trichoderm a harzianum for managing fusarium wilt of banana. Agric Ecosyst Environ. 2004;103:259-63.

31. Nel B, Steinberg C, Labuschagne N, et al. The potential of nonpathogenic Fusarium oxysporum and other biological control organisms for suppressing fusarium wilt of banana. Plant Antpathol. 2006;55(2):217-23.

32. Ling B, Li Q, Xu ZH, et al. Responses of beneficial Bacillus amyloliquefaciens SQR9 to different soilborne fungal pathogens through the alteration of antifungal compounds production. Front Micorbiol. 2014;5:636.

\section{Publisher's Note}

Springer Nature remains neutral with regard to jurisdictional claims in published maps and institutional affiliations.

\section{Ready to submit your research? Choose BMC and benefit from:}

- fast, convenient online submission

- thorough peer review by experienced researchers in your field

- rapid publication on acceptance

- support for research data, including large and complex data types

- gold Open Access which fosters wider collaboration and increased citations

- maximum visibility for your research: over $100 \mathrm{M}$ website views per year

At BMC, research is always in progress.

Learn more biomedcentral.com/submissions 